\title{
Seasonal ocean temperature and the survival of first-year little penguins Eudyptula minor in south-eastern Australia
}

\author{
Leesa A. Sidhu' ${ }^{1}$, Peter Dann ${ }^{1,2, *}$, Lynda Chambers ${ }^{3}$, Edward A. Catchpole $^{1}$ \\ ${ }^{1}$ School of Physical, Environmental and Mathematical Sciences, \\ University of New South Wales at the Australian Defence Force Academy, Canberra ACT 2600, Australia \\ ${ }^{2}$ Research Department, Phillip Island Nature Parks, PO Box 97, Cowes, Phillip Island, Victoria 3922, Australia \\ ${ }^{3}$ Centre for Australian Weather and Climate Research, Bureau of Meteorology, GPO Box 1289, Melbourne, Victoria 3001, \\ Australia
}

\begin{abstract}
Ocean temperature has been shown to be related to various demographic parameters in several seabird species, but ultimately its influence on breeding success and survival are paramount. The timing and success of breeding of little penguins Eudyptula minor in south-eastern Australia have been shown to correlate with local sea-surface temperatures (SST) and the east-west sea-temperature gradient across Bass Strait several months earlier. However, the causal links between ocean temperature and these demographic variables are not readily apparent due to their lagged nature. Using $41 \mathrm{yr}$ of data on little penguins in south-eastern Australia, we carried out a mark-recapture analysis to examine if the changing SST and sea-temperature gradient (east-west difference between 2 locations in Bass Strait) are associated with survival probability in the first year of life. First-year survival is correlated with (1) an east-west sea-temperature gradient in Bass Strait in the winter after fledging, with an increased temperature gradient associated with decreased survival and (2) the mean SST in the autumn after fledging, with warmer seas associated with increased survival. SST alone does not provide the best model for explaining first-year survival. Projections suggest that SST in south-eastern Australia and sea-temperature gradient in Bass Strait will both increase due to global warming. The net effect of an increased sea-temperature gradient in winter (which has a negative influence) and increased SST in autumn (which has a positive influence) on first-year survival is uncertain, given the current lack of knowledge concerning the relationship between the sea-temperature gradient and SST in Bass Strait.
\end{abstract}

KEY WORDS: Eudyptula minor $\cdot$ Little penguin $\cdot$ Mark-recapture $\cdot$ First-year survival $\cdot$ Sea-surface temperature $\cdot$ Temperature gradient $\cdot$ Climate change $\cdot$ Phillip Island $\cdot$ South-eastern Australia

\section{INTRODUCTION}

Climatological variables play a role in the functioning of marine ecosystems and the productivity of species at both large and local scales (Mills et al. 2008, Sydeman \& Bograd 2009, Ainley \& Hyrenbach 2010, Ainley et al. 2010). Changes in regional sea temperature have been shown to influence the distribution, phenology, productivity and survival of seabirds
(Inchausti et al. 2003, Frederiksen et al. 2007, Irons et al. 2008, Cullen et al. 2009, Moe et al. 2009, Ainley et al. 2010, Barbraud et al. 2011, Chambers et al. 2011). These influences can be positive or negative and usually precede life-history events by months or even years (Mickelson et al. 1992, Guinet et al. 1998, Barbraud et al. 2011). These lags suggest that the mechanisms are operating on productivity at trophic levels below the apex or mesopredator levels of most sea- 
birds (Cullen et al. 2009), rather than having immediate effects on the physiology or behaviour of the birds. More immediate effects of temperature on seabirds may involve relationships between temperature and the distribution and availability of prey. For example, Ropert-Coudert et al. (2009) have proposed that the presence of thermoclines may assist foraging success in little penguins Eudyptula minor.

Local-scale climate signals from the marine environment (i.e. temperature, wind and precipitation) also affect demographic processes in some species (Aebischer et al. 1990, Kitaysky et al. 2000, Gjerdrum et al. 2003). In other cases, reproduction and recruitment can be influenced by both large- and localscale climatic processes (Weimerskirch et al. 2003, Sandvik et al. 2005, Votier et al. 2005).

Several studies have shown relationships between sea temperature in Bass Strait and the breeding of little penguins from Phillip Island in south-eastern Australia (Mickelson et al. 1992, Cullen et al. 2009). Mickelson et al. (1992), who defined the east-west sea-surface temperature (SST) gradient across Bass Strait used here as the difference in SST between 2 sites in Bass Strait (Site 1: 39 to $40^{\circ} \mathrm{S}, 145$ to $146^{\circ} \mathrm{E}$ and Site 2: 38 to $39^{\circ} \mathrm{S}, 149$ to $150^{\circ} \mathrm{E}$ ) (Fig. 1), found that a decreased east-west sea-temperature gradient (i.e. warmer west and/or cooler east SST) was associated with increased weights of adults 4 mo later and a July to August decrease in sea-temperature gradient was associated with an early start to egg-laying in Sep- tember to October. They proposed that these were due to the cooler waters from the west, with their higher levels of nutrients and associated higher levels of primary and secondary production, penetrating further east into central Bass Strait and closer to Phillip Island (Mickelson et al. 1992). Cullen et al. (2009) found that the timing and success of breeding was correlated with local SST in autumn a few months prior to the onset of breeding. Their model predicted an early egg-laying date, higher average chick mass at fledging and more chicks produced per breeding pair when SST in Bass Strait is warmer than average in March. They proposed 2 potential mechanisms for the lagged positive relationship between SST and breeding which were that warmer SST allowed for a longer and hence more productive breeding period or that the warmer SST provided conditions that translated into greater availability or quality of food.

SST around south-eastern Australia is influenced by waters from 4 regions (Gibbs 1992), and, in Bass Strait, there are 2 primary influences on SST: the East Australian Current (EAC) and the easterly flowing mixture of warm, nutrient-poor subtropical water and the nutrient-rich cool subantarctic water (Gibbs 1992). Bass Strait water around Phillip Island originates mostly from the west, flowing east across South Australia along the Australian south coast as lownutrient subtropical water from the Great Australian Bight (Fig. 1). The EAC flows southwards, bringing eddies of warm nutrient-poor tropical water from the

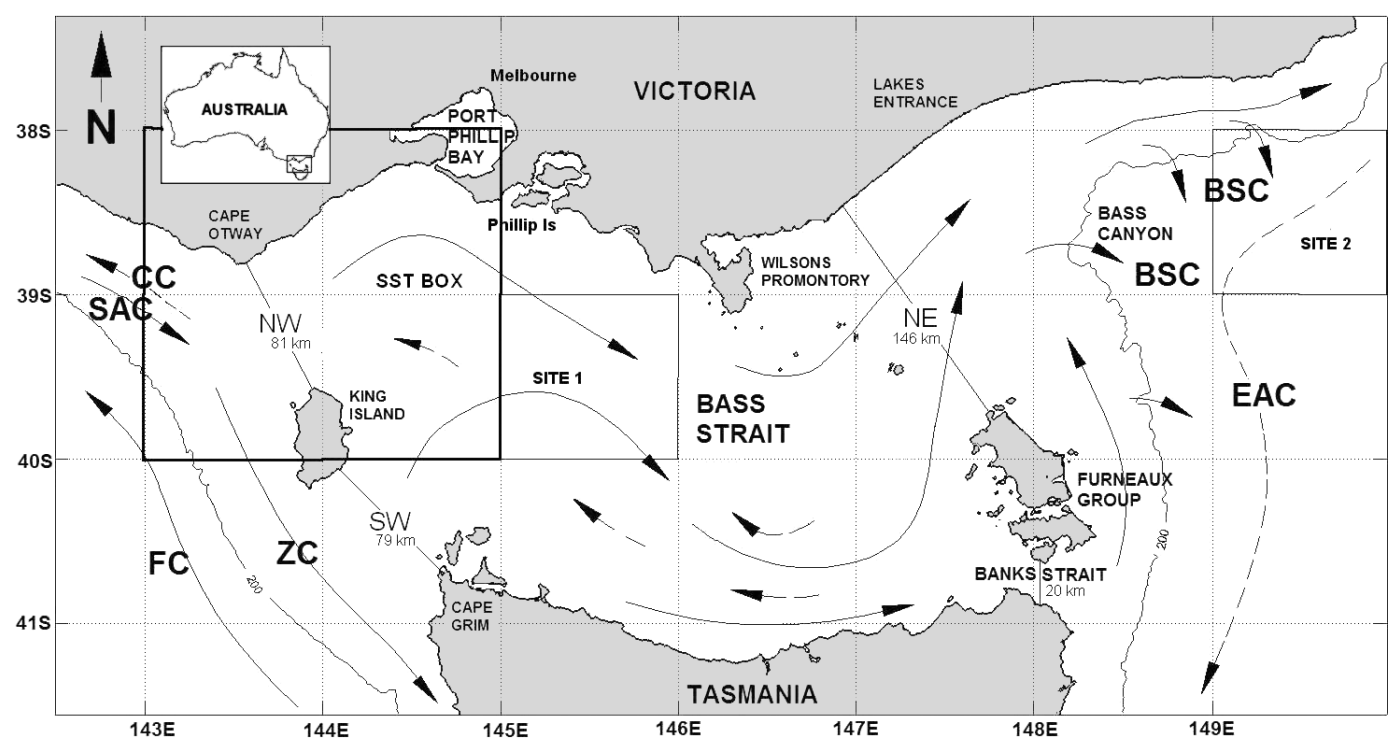

Fig. 1. Study area showing the locations of Phillip Island $\left(38^{\circ} 31^{\prime} \mathrm{S}, 145^{\circ} 08^{\prime} \mathrm{E}\right)$, the sea-surface temperature (SST) box, and the 2 sites used to measure the sea-temperature gradient in Bass Strait. The SST box covers 143 to $145^{\circ} \mathrm{E}, 38$ to $40^{\circ} \mathrm{S}$; Site 1 covers 145 to $146^{\circ} \mathrm{E}, 39$ to $40^{\circ} \mathrm{S}$; Site 2 covers 149 to $150^{\circ} \mathrm{E}, 38$ to $39^{\circ} \mathrm{S}$. Also shown is a schematic representation of the currents in the Bass Strait region (from Sandery 2007). Summer currents are denoted by dashed lines. EAC: East Australian Current; SAC: South Australian Current; ZC: Zeehan Current; FC: Flinders Current; CC: summer Coastal Current; BSC: Bass Strait Cascade 
Pacific Ocean into eastern Bass Strait (Ridgway \& Hill 2009). Ridgway \& Hill (2009) predicted that the EAC will become stronger in the future and extend further south. In the south and in deep water beyond the continental shelf on the western side of Bass Strait, the cold nutrient-rich subantarctic water originates from below the Subtropical Convergence Zone and the eastward flowing Antarctic Circumpolar Current. The interaction of these 4 water masses, which are influenced by the seasonal wind patterns, has a significant impact on the sea temperature of Bass Strait (Gibbs 1992). Within Bass Strait, the extent and influence of currents and water masses vary seasonally and inter-annually (Sandery 2007) (Figs. 1 \& 2). Intrusions of cooler, nutrient-rich water through the western entrances of Bass Strait occur mainly during winter and spring and are driven primarily by local and remote winds (Newell 1966, Tomczak 1985, 1987, Gibbs et al. 1986, Middleton \& Black 1994). Two areas of high productivity occur in northern Bass Strait, a localised coastal upwelling in the west (Bonney Upwelling) and a nutrient enrichment zone in the east (Bulman et al. 2011).

There is no post-fledging parental care in little penguins (P. Dann pers. obs.), and the apparent survival in the first year of life is low at $0.165(\mathrm{SE}=0.007$; Sidhu 2007). The peak mortality period for first-year birds is in the late summer and autumn (February to April) following fledging (Dann et al. 1992). Recoveries of flipper-banded first-year birds indicate that

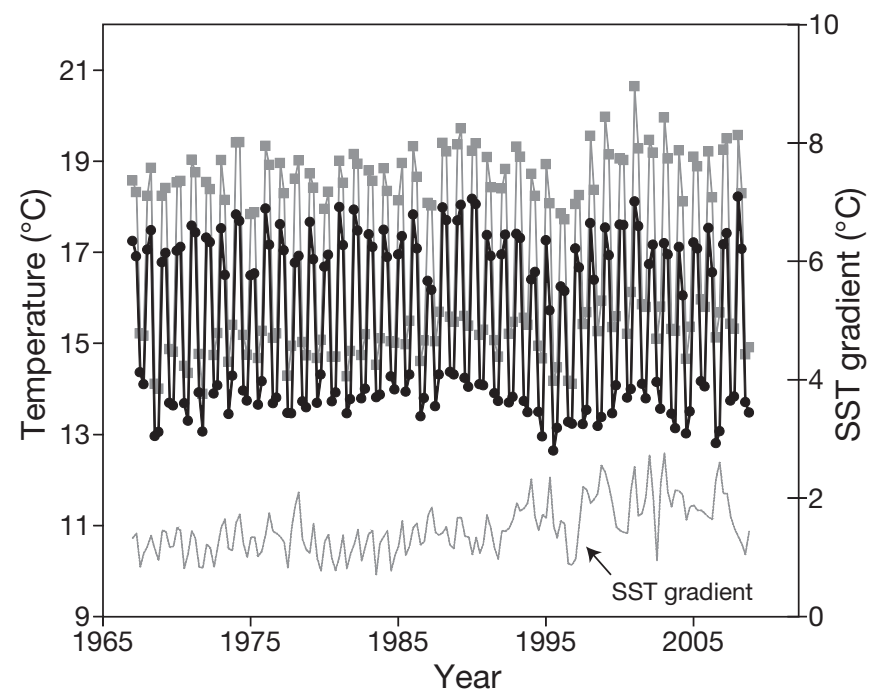

Fig. 2. Seasonal and inter-annual variability in sea-surface temperature (SST) in the Bass Strait region over the period of the study. SST at Site 1 (Fig. 1) in western Bass Strait is represented by the solid black line and circles; SST at Site 2 in eastern Bass Strait by the solid grey line and squares. The difference between SST at Site 2 and Site 1, the seatemperature gradient, is also indicated they travel several hundred kilometres west of Phillip Island in the months post-fledging, possibly to take advantage of the more nutrient-rich waters associated with the edge of the continental shelf and the Bonney Upwelling (Dann et al. 1992). This area is beyond the usual foraging areas of adults from Phillip Island (Dann et al. 1992, Dann \& Norman 2006, McCutcheon et al. 2011) and may be indicative of more productive feeding areas. The restricted foraging range of penguins suggests that they are likely to have more precise responses to local ocean conditions in comparison to volant seabirds.

Given the potential effect of SST on the survival of little penguins, projected changes to ocean temperature may well have a significant effect on the viability of this species in Bass Strait, one of the strongholds for little penguins (Dann et al. 1996). Predictions are for the eastern side of Bass Strait to warm more than the western side (Hobday et al. 2008). By 2070, ocean warming around Australia is projected to be in the range of 2 to $3^{\circ} \mathrm{C}$, with the greatest warming off south-eastern Australia $\left(3^{\circ} \mathrm{C}\right)$ (Fig. 5 in Poloczanska et al. 2007). In fact, Poloczanska et al. (2007) make the following prediction: 'Waters around Australia are projected to warm by 1 to $2^{\circ} \mathrm{C}$ by the 2030s and 2 to $3^{\circ} \mathrm{C}$ by the $2070 \mathrm{~s}$ (Fig. 5 [in Poloczanska et al. 2007]). The CSIRO climate model projects the greatest warming off southeast Australia, and this is the area of greatest warming during this century in the entire Southern Hemisphere. This Tasman Sea warming is associated with systematic changes in the surface currents on the east coast of Australia, including a strengthening of the EAC and increased southward flow as far south as Tasmania (Fig. 5 in Poloczanska et al. 2007). This feature is present in all IPCC climate model simulations, with only the magnitude of the change differing among models. Changes in currents leading to the Tasman Sea warming observed to date are driven by a southward migration of the high-latitude westerly wind belt south of Australia, and this is expected to continue in the future' (Poloczanska et al. 2007, p. 414).

Relationships have previously been reported between sea temperature and survival of adult seabirds (e.g. Harris et al. 2005, Rolland et al. 2008, Barbraud et al. 2011), but much less commonly with immature birds (Votier et al. 2008). Votier et al. (2008) found a weak negative relationship between winter SST and recruitment in immature common guillemots Uria aalge. An additional motivation for the present study was that since Mickelson et al. (1992) and Cullen et al. (2009) observed relationships between local SST or sea-temperature gradient and breeding variables for 
little penguins, an examination of the potential relationship between sea temperature and survival is the next logical step in building models to determine how sea temperature change may influence little penguins. Although our work is focussed on 1 species in 1 region, the significance of this demographic study of a marine mesopredator and the relationship with ocean temperatures over an unusually long time series has implications for marine ecosystems worldwide.

We use a 41 yr mark-recapture dataset from a breeding colony of little penguins on Phillip Island to examine the relationships between the annual firstyear survival probability and local SST and sea-temperature gradient in Bass Strait. We hypothesise that increased SST is associated with increased first-year survival, in light of the significant positive relationship found between SST and the timing and success of breeding by Cullen et al. (2009). Given that Mickelson et al. (1992) found that decreased temperature gradient was associated with increases in adult weight and earlier egg-laying, we form a second hypothesis that a decreased sea-temperature gradient is also associated with increases in first-year survival.

\section{METHODS}

\section{Mark-recapture analysis}

A total of 54484 little penguins Eudyptula minor were marked with devices that allowed them to be later identified: 41660 with flipper bands between 1968 and 2003, and 12824 with injected electronic transponders between 1987 and 2007. Initial marking and subsequent recaptures took place at Phillip Island $\left(38^{\circ} 31^{\prime} \mathrm{S}, 145^{\circ} 08^{\prime} \mathrm{E}\right)$ in Victoria, south-eastern Australia, with the recapture data extending until 2008. These data comprise 34483 birds marked as chicks and 20001 marked as adults of unknown age. We have summarised these data into 12 mo cohorts ( 1 July to 30 June). Here 'mark' refers to the initial application of a tag (band or transponder), and 'recapture' denotes a subsequent live encounter (Catchpole et al. 1998, Sidhu et al. 2007). We use biologically realistic age structures for the model parameters that fit the lifestyles of little penguins (Sidhu et al. 2007). Recoveries of dead birds have not been included in the analysis since dead recovery data are not available for transpondered birds. A joint analysis of recovery-recapture data for banded birds and recapture-only data for transpondered birds could have been undertaken. However, Sidhu (2007) showed that the survival estimates of little penguins obtained under recovery-recapture and recaptureonly analyses were almost identical and there was no improvement in the standard error when the recovery information was added.

The model parameters used are the annual survival probabilities and the recapture probabilities, defined as follows. Let $\phi_{i, j}$ be the probability that a bird survives the $j$ th calendar year, given it was alive at the start of the year, where $i=1$ in the first year of life and $i=2$ for each subsequent year of life. P. Dann et al. (unpubl. data) showed that the mortality rate of banded birds is about one-third greater than that of transpondered birds. Therefore, the annual survival probabilities for both the first year of life and subsequent years are allowed to depend on whether a bird was flipper-banded or transpondered. At the sth stage of modelling, we fit $\operatorname{logit}\left(\phi_{1, j}\right)=a_{0}+a_{1} V_{1, j}+\ldots+$ $a_{S} V_{S, j}+b B$, where $\operatorname{logit}(x)=\log [x /(1-x)]$ is the logodds ratio or logistic transform, the $V_{S, j}$ are the SST or sea-temperature gradient covariates, $a_{0}, a_{1}, \ldots, a_{S}$ and $b$ are unknown parameters, and $B=1$ for banded birds and $B=0$ otherwise. At the second stage of modelling, we also incorporate a quadratic effect for the best-fitting covariate. When modelling first-year survival $\phi_{1, j}$, we allow adult survival $\phi_{2, j}$ to be fully time-varying, but with the time variation being the same for banded and transpondered birds, denoted as $\operatorname{logit}\left(\phi_{2, j}\right)=d_{j}+e B$, where $d_{j}$ and $e$ are unknown parameters. We write this symbolically as $\phi_{2}(t+B)$, where $t$ denotes time.

Let $p_{i, j}$ be the probability that a bird is recaptured in the $(j+1)$ th breeding season, given it was alive then, where $i=1$ in the first year of life, $i=2$ in the second year, and $i=3$ in each subsequent year. In all of the models examined here, we use an 'age + time' model for recapture, with

$$
\operatorname{logit}\left(p_{i, j}\right)=f_{i}+g_{j}
$$

Here $f_{1}, f_{2}$ and $f_{3}$ are constants specific to the age groups, whereas $g_{j}$ represents time-dependent parameters. This implies that time variation of the recapture probability is the same for each age group.

This model is a realistic reflection of the little penguin lifestyle. Separate annual survival probabilities are used for the first and subsequent years of life, as first-year birds are particularly at risk due to inexperience and internal parasitic loads (Dann 1992, Dann et al. 1992, Harrigan 1992). Furthermore, since young birds go to sea and return to Phillip Island to breed at 2 or 3 yr of age, separate recapture probabilities are needed for the first, second, and subsequent years of life (Reilly \& Cullen 1981, Dann \& Cullen 1990, Sidhu 2007). 
The likelihood is formed as in Burnham (1993) and Catchpole et al. (1998). We redefine the parameters for this paragraph only, so that the subscript $i$ in $\phi_{i, j}$ and $p_{i, j}$ refers to the $i$ th bird. The observed markrecapture history of this bird is shown as an indicator vector $h_{i}$ of length equal to the length of the study (here 42), with an entry 1 indicating that the bird was seen (initial capture or subsequent recapture) and a 0 that it was not seen. Let $c_{i}$ and $k_{i}$ denote the years of first and last capture, respectively, and let $\chi_{r}$ denote the probability of never being seen again after year $r$. We write the probability of the history $h_{i}$, conditional on the initial capture at $C_{i}$, as:

$$
L_{i}=\left\{\prod_{j=C_{i}}^{k_{i}-1} \phi_{i, j} p_{i, j}{ }^{h_{i, j+1}}\left(1-p_{i, j}\right)^{1-h_{i, j+1}}\right\} \chi_{k_{i}}
$$

and this is the likelihood for bird $i$. The likelihood for the whole data set is the product $L=\prod_{i} L_{i}$ over all birds. This is known as the Cormack-Jolly-Seber model (Cormack 1964, Jolly 1965, Seber 1965). For further details of our methods see Ganendran et al. (2011) and Sidhu et al. (2011). The analysis is conditional on the observed covariate values, and so does not assume anything about their autocorrelation structure. The main assumptions in forming the likelihood are that the population is homogeneous, and that birds behave independently of each other and of their actions in previous years (for example, that breeding in one year does not influence the likelihood of breeding and hence being captured in following years). The likelihood is then maximised (or, equivalently, the negative of the log-likelihood is minimised) using the Matlab fmincon function. Matlab code is available from http://pems.unsw.adfa.edu .au/staff/profiles/catchpole_t.

Model selection is via the Akaike information criterion (AIC; Burnham \& Anderson 2002). The fit of a model with log-likelihood 1 is measured by the proportion of the total (time) deviance explained, $\left(1-l_{0}\right) /\left(l_{\text {full }}-l_{0}\right)$, where $l_{0}$ is the log-likelihood of the null model, with first-year survival depending only on whether or not the bird was banded, and $l_{\text {full }}$ is that of the full model, with fully time-varying first-year survival, of the same form as that for adult survival (McCullagh \& Nelder 1989, p. 33).

\section{Seasonal SST and sea-temperature gradient}

We use seasonal SST and sea-temperature gradient as covariates for first-year survival. Seasonal SST is the average over each 3 mo season (e.g. for autumn by averaging over March, April and May) for the region situated between 38 and $40^{\circ} \mathrm{S}, 143$ and $145^{\circ} \mathrm{E}$, as in Cullen et al. (2009). The east-west sea-temperature gradient is calculated as in Mickelson et al. (1992) and described above. See Fig. 1 for locations of sites used in this calculation. Fig. 2 illustrates the time variation of SST at each site and of the gradient. We calculate the seasonal sea-temperature gradient by averaging over each 3 mo season.

We use seasonal rather than monthly values to decrease the number of covariates, and so reduce the chances of producing spurious correlations (Federer 1955). In addition, seasonal rather than monthly values are more appropriate, since the phenomena which cause mortality of little penguins tend to span months, but are less likely to span seasons (Dann 1992).

Mickelson et al. (1992) and Cullen et al. (2009) identified lags of several months in the effects of sea temperature on breeding in little penguins. To account for lagged effects, we allow first-year survival over calendar year $j$ to depend on mean seasonal SST and mean seasonal sea-temperature gradient over 6 seasons (18 mo), from the winter preceding the breeding event (1 June to 31 August in calendar year $j-1$ ) denoted by 'WiP', to spring in the current year (1 September to 30 November in calendar year $j$ ) denoted by 'SpC'.

\section{RESULTS}

First-year and adult survival of little penguins Eudyptula minor both vary appreciably with time (see Fig. 3). Both vary to a similar extent on a logistic scale, and the correlation between them is quite low (0.23 on a logistic scale). It thus appears that the causes of variation in adult survival are different from those affecting first-year birds. In the present paper we concentrate on first-year birds.

The best-fitting first-stage model is that of the mean east-west sea-temperature gradient in the current winter (grdWiC; Table 1), with the negative regression coefficient $b_{1}=-0.350( \pm 0.054 \mathrm{SE})$ indicating that a higher average sea-temperature gradient in the winter following fledging is associated with reduced firstyear survival (see Fig. 4). Indeed, apart from the model including the sea-temperature gradient in the current summer (which is no improvement on the null model in terms of AIC), all of the regression coefficients corresponding to the temperature gradient are negative, indicating that an increasing east-west seatemperature gradient - that is, with warming eastern SST and/or cooling western SST — is associated with lower first-year survival probabilities. 


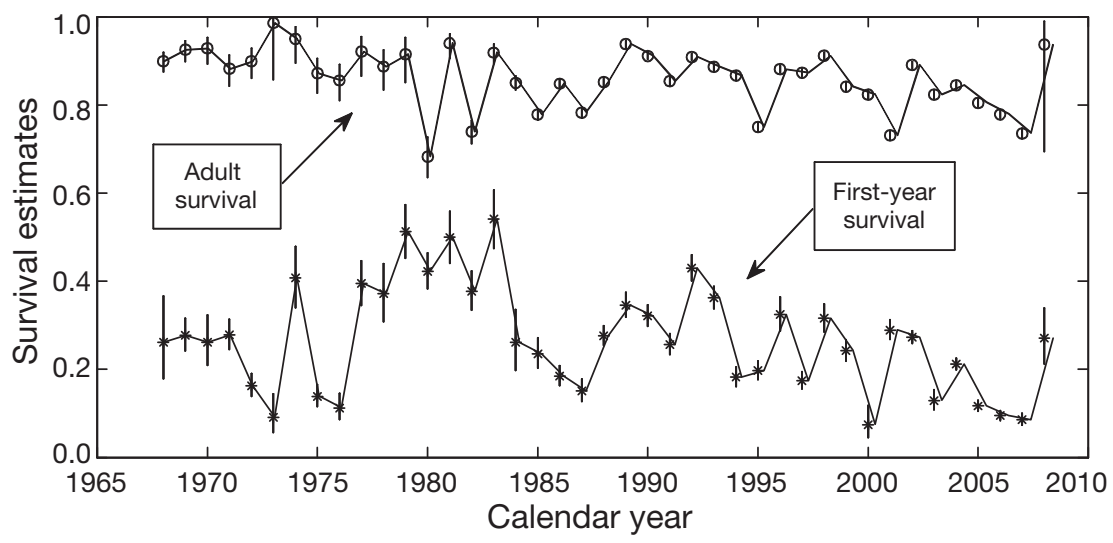

Fig. 3. Eudyptula minor. The variation over time for first-year and adult survival probabilities for unbanded (transpondered) birds under the full model, with an age + time structure for the recapture probability as in Eq. (1) and a survival age structure of $\phi_{1}(t+B), \phi_{2}(t+B)$. Vertical bars represent $1 \mathrm{SE}$ on each side of the estimate (back-transformed from the logistic scale)

grdWiC and sstAuC influence firstyear survival independently: their correlation is low, with an absolute value of $<0.20$, and the regression coefficient of grdWiC is only slightly changed, at $b_{1}=-0.280( \pm 0.056)$, from its value at the first stage. Although the inclusion of both covariates is well justified in terms of AIC (Table 1), grdWiC accounts for only $7.5 \%$ of the deviance (time variation) at the first stage, and, at the second stage, sstAuC accounts for a further $3.7 \%$. This lack of explanatory power can be seen in Fig. 4 which shows that, over the whole range of grdWiC, survival is only predicted to range from 0.15 to 0.24 (for transpondered birds), whereas

Table 1. Eudyptula minor. Akaike's information criterion (AIC) values for various models for first-year survival probabilities. All models have a recapture probability model of age + time as in Eq. (1) and a survival age structure of $\phi_{1}(x+B)$, $\phi_{2}(t+B)$, where $B$ denotes whether the bird was banded and $x$ is one or more of the sea-surface temperature (denoted by 'sst') or sea-temperature gradient ('grd') covariates, ranging from WiP ('previous winter', i.e. the winter preceding the breeding event) to $\mathrm{SpC}$ ('current spring', i.e. the spring in the chick's first year of life). At the first stage only a single covariate is used. The second stage uses the best model (shown in bold) from the first stage, plus each of the other covariates, and so on. The AIC of the null model is 816.1. The signs of the regression coefficients corresponding to each added covariate are also given. Su: summer; Au: autumn

\begin{tabular}{|c|c|c|c|c|c|c|}
\hline \multirow{3}{*}{$\begin{array}{l}\text { Covari- } \\
\text { ate }(x)\end{array}$} & \multirow{2}{*}{\multicolumn{2}{|c|}{$-1 \mathrm{st}$}} & \multirow{2}{*}{\multicolumn{2}{|c|}{$\begin{array}{l}\text { Stage } \\
\text { 2nd }\end{array}$}} & \multirow{2}{*}{\multicolumn{2}{|c|}{$3 \mathrm{rd}$}} \\
\hline & & & & & & \\
\hline & AIC & Sign & AIC & Sign & AIC & Sign \\
\hline sstWiP & 811.99 & + & 777.07 & + & 758.63 & - \\
\hline sstSpP & 804.39 & + & 774.16 & + & 758.47 & - \\
\hline sstSuC & 816.47 & + & 774.94 & + & 756.83 & - \\
\hline sstAuC & 779.66 & + & 756.86 & + & & \\
\hline sstWiC & 799.41 & + & 776.42 & + & 750.90 & - \\
\hline sstSpC & 816.68 & + & 777.66 & - & 748.61 & - \\
\hline grdWiP & 816.45 & - & 777.69 & + & 758.45 & + \\
\hline grdSpP & 811.53 & - & 777.24 & - & 758.59 & - \\
\hline grdSuC & 816.52 & + & 775.26 & + & 752.29 & + \\
\hline $\operatorname{grdAuC}$ & 809.20 & - & 776.72 & - & 756.92 & + \\
\hline grdWiC & 775.88 & - & & & & \\
\hline grdSpC & 818.10 & - & 759.53 & + & 740.73 & + \\
\hline
\end{tabular}

At the second stage, allowing for the sea-temperature gradient in the current winter, the best fitting covariate is SST in the current autumn (sstAuC in Table 1). The regression coefficient of sstAuC, $b_{2}=$ $0.161( \pm 0.035 \mathrm{SE})$, means that a higher average SST in the autumn following fledging is associated with increased first-year survival. The 2 covariates 'observed' time-dependent estimates range from 0.07 to 0.54 . There is no evidence for a quadratic rather than a linear effect of temperature gradient on survival — the AIC value changes from 775.9 to 777.5 when a quadratic term is added.

At the third stage, the next best covariate is the seatemperature gradient in the current spring $\left(\operatorname{grdSpC} \mathrm{C}_{i}\right.$ Table 1). The regression coefficients of grdWiC and sstAuC are $b_{1}=-0.429( \pm 0.066 \mathrm{SE})$ and $b_{2}=0.161$ $( \pm 0.036)$, respectively. The regression coefficient of grdSpC is $b_{3}=0.260( \pm 0.061)$, indicating that a higher east-west sea temperature gradient in the spring of the first-year of life is associated with increased survival. This result is in contrast with our findings in the earlier stages of the modelling. However, there is a substantial correlation (coefficient $=0.76$ ) between grdWiC and grdSpC, which has caused the observed changes in the regression coefficients, and so it is unwise to include both of these covariates in the regression. The next best covariate, sstSpC, has low correlations with grdWiC and sstAuC. However, it is hardly worth including, as it increases the proportion of deviance explained by the model from $11.2 \%$ to only $11.3 \%$.

SST and the sea-temperature gradient are both forecast to increase as a result of global warming, since eastern Bass Strait is predicted to warm more than western Bass Strait (Hobday et al. 2008). Therefore, the 2 effects we have found will act in opposite directions. For example, if sstAuC and grdWiC are both at their average values over the $41 \mathrm{yr}$ of the data, the forecast value of first-year survival for a transpondered bird is $0.202( \pm 0.007 \mathrm{SE})$. If sstAuC increases by $2^{\circ} \mathrm{C}$, while grdWiC remains fixed, this value increases to $0.259( \pm 0.016)$. If, on the other hand, sstAuC remains fixed, while grdWiC increases by 


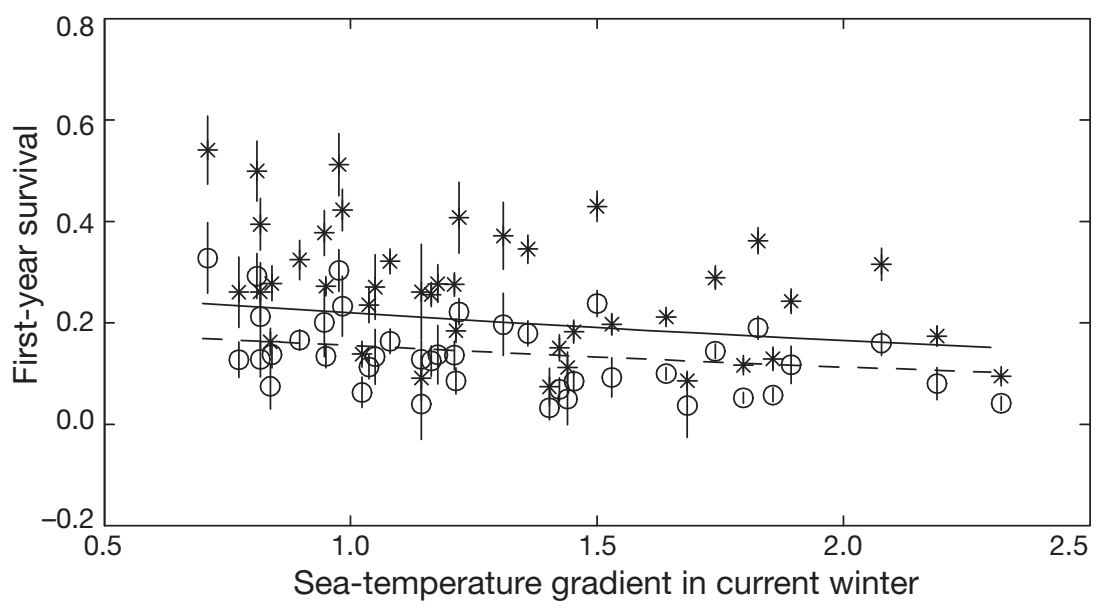

Fig. 4. Eudyptula minor. The relationship between time-dependent first-year survival under model $\phi_{1}(t+B)$ and the sea-temperature gradient in the current winter, for banded (open circles) and unbanded (stars) birds. The lines show the predicted values for first-year survival for banded (dashed line) and unbanded (solid line) birds from the fitted model $\phi_{1}(\operatorname{grdWiC}+B)$

It appears that SST alone is not the best means of capturing the processes operating on first-year survival. The incorporation of a temperature gradient as a covariate for first-year survival provides both a better fit to the data and a fuller understanding of the marine environment in Bass Strait than SST alone, as it incorporates the effects of the EAC, water movement from the west and of prevailing winds on SST. A temperature gradient in Bass Strait in winter is likely to be indicative of both the extent of the EAC in the east and the amount of wind-driven cool water movement from the west.

Most mortality of first-year little penguins occurs in the period from late autumn to winter (Dann 1992), which is when the temperature gradient has its

$1^{\circ} \mathrm{C}$, the survival forecast decreases to $0.160( \pm 0.008)$. If both changes occur, then the survival would increase to $0.209( \pm 0.017)$. We have used a smaller example change for the gradient as, being a difference between sea temperatures, it is likely to change by less than SST. The example increases in sstAuC and grdWiC are both within the range of the observed data. The standard errors stated here do not account for the uncertainty in the climate forecasts.

\section{DISCUSSION}

First-year survival of little penguins Eudyptula minor bred on Phillip Island is most strongly related to the east-west sea-temperature gradient within Bass Strait in the winter after their main fledging period. Reduced survival is associated with an increase in the east-west temperature gradient associated with more rapid warming in the east of Bass Strait than in the west (Fig. 2). Mickelson et al. (1992) found that a winter increase in the sea-temperature gradient had negative effects on the breeding of the same population of little penguins. They hypothesised that a decrease in gradient was associated with stronger westerly winds in winter, bringing nutrient-rich water into Bass Strait which enhanced local productivity and led to earlier and more successful breeding. Ganendran et al. (2011) considered wind direction and survival of little penguins, finding a positive relationship between southerly winds in the winter before the chicks were born and a negative one with easterly winds in the preceding summer. most apparent influence on their survival. If strong prevailing westerly winds contribute to an increased gradient in winter, by bringing cooler water into western Bass Strait, then the increased mortality of first-year penguins may be related to the prevalence of strong winds driving these incursions of cooler water and affecting their foraging efficiencies by reducing thermoclines (Ropert-Coudert et al. 2009). Conversely, if the increased gradient is due to a greater incursion of warmer water into Bass Strait from the east, then substantial local reductions may result in the availability of cool-water prey species. Both hypotheses are supported by the strong tendency for fledged birds from Phillip Island to head west to the cooler side of Bass Strait (Dann 1992), either as avoidance of warmer water in the east or tracking nutrientrich cooler waters coming in from the west. The latter is supported by the positive association between the survival of fledged birds and autumn SST.

Over the period of this study, the sea-temperature gradient increased at around $0.02^{\circ} \mathrm{C} \mathrm{yr}^{-1}(\mathrm{p}<0.001)$, consistent across all seasons. SST in Site 1, western Bass Strait, showed no significant warming trend, whereas Site 2, eastern Bass Strait, had a warming trend in summer, winter and spring, at a rate similar

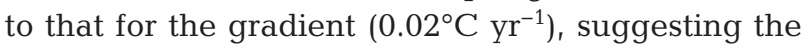
increased sea-temperature gradient was due mainly to a greater warming in the east, perhaps due to the influence of a stronger EAC.

Replacing the best first-stage covariate (grdWiC) with the corresponding SST from Site 1 only (west side of Bass Strait, see Fig. 1) and then Site 2 only (east) indicates that the contribution is almost entirely 
from the west side. Indeed Site 2 is a very poor predictor for first-year survival. This result is in agreement with our earlier explanation regarding inflowing nutrients from the west. In general, the sea-temperature gradient and the SST at Site 1 are not well correlated, and the sea-temperature gradient predicts first-year survival much better than the SST at Site 1.

Although the effect of the gradient on survival is mostly due to the influence of SST in Site 1 (the western side), the effect of the gradient is not entirely the same as that for Site 1. So there is some complexity in the system that is not picked up when just considering SST in Site 1. Given that the gradient has an effect different from SST, it is important to consider the possible effects of an increase in this variable.

Once the sea-temperature gradient in the winter after fledging has been included as a covariate for first-year survival, there is still a relationship between first-year survival and SST in the autumn following fledging. These 2 covariates influence first-year survival independently -1 negatively and 1 positively. It is not surprising that there is a relationship between juvenile survival and environmental conditions in autumn. Most chicks are banded prior to fledging in December to February (Reilly \& Cullen 1982), and, by the beginning of autumn, almost all of the newly fledged birds will have gone to sea. Autumn is the peak mortality period for these young birds that are inexperienced in finding food (Dann et al. 1992) and have no post-fledging parental care, and SST may well have an influence on the availability of food at this critical time. Cullen et al. (2009) argued that the importance of warmer SST in the autumn before breeding began may be due to increased productivity or juvenile fish survival increasing the availability of food for breeding. These mechanisms seem less applicable to the survival of first-year penguins as the significant periods for SST were during their critical survival period rather than some months earlier. However, increased autumn temperature may be associated with enhanced larval fish survival (Zeldis et al. 2005, Hinrichsen et al. 2007) and provide a possible mechanism for influencing first-year penguin survival.

Relationships have previously been reported between sea temperature and survival of adult seabirds (e.g. Harris et al. 2005, Rolland et al. 2008, Barbraud et al. 2011) and much less commonly with immature birds (Votier et al. 2008). The links between seabird survival and SST may either occur in the same season or be lagged so that the important periods of SST precede the mortality periods by months or even years (Votier et al. 2008, Barbraud et al. 2011). Here we have found consecutive independent seasonal re- sponses, whereby the autumn SST as the birds fledge has a lesser and positive effect on survival and the temperature gradient in winter has a negative and greater influence.

Poloczanska et al. (2007) provide a prediction for the SST in the region of Site 2 (Fig. 1), with an increase of up to $3^{\circ} \mathrm{C}$ by 2070 . However, since there are no existing forecasts specifically for Bass Strait, we are unable to reliably predict the SST at Site 1, and so any prediction of the change in the seatemperature gradient would be highly speculative.

There are relatively few climatic variables available for this time series, and we chose ocean temperature as it could play a pivotal role in the trophodynamics of Bass Strait and hence show strong links with penguin survival. We need to continue to explore the utility of other variables in the first instance and then combinations of variables with a view to developing a model with more predictive power. Food availability seems the most likely proximate factor determining first-year survival, and a suite of biotic and abiotic factors are likely to ultimately determine food availability. Data on prey availability would be desirable. The abiotic factors presumably include oceanographic and climatic variables, although, based on the present study, sea temperature alone is unlikely to be sufficient. Future statistical approaches will consider looking at measures associated with marine productivity such as chlorophyll $a$, alone or in tandem with temperature. Although the time series available for chlorophyll $a$ is of a shorter duration than the penguin demographic variables, this covariate may be more closely linked to penguin survival than temperature alone.

At present there is considerable uncertainty as to the expected magnitude of change in the east-west Bass Strait temperature gradient under global warming scenarios and its rate of increase relative to changes in SST. This reduces our capacity further to predict the likely overall impact of future changes in oceanographic conditions on first-year survival, given that our predictive capacity is already low due to the low explanatory power of our best model (accounting for only $11 \%$ of time variation). There is therefore great uncertainty in the magnitude of the future change in mean penguin survival with changing ocean temperature. While 'noise' may well have engulfed the true 'signal', changes in the stochastic fluctuations average out over the long term, allowing the underlying change in signal to emerge. Hence, changing ocean temperatures and the possible resulting changes in mean survival could have substantial long-term demographic effects. 
Acknowledgements. The authors are indebted to the staff of the Phillip Island Nature Parks, Australia, particularly Ros Jessop and Leanne Renwick, and to members of the Penguin Study Group and the Australian Bird and Bat Banding Scheme (ABBBS) for providing some of the data upon which this study is based. The ABBBS also kindly provided the flipper-bands during the earlier years of the study. The Department of Sustainability and Environment in Victoria, Australia, provided the permits to handle and mark the penguins. We are also grateful to Paul Sandery for providing Fig. 1. Three anonymous referees provided helpful advice on a draft of this paper.

\section{LITERATURE CITED}

Aebischer NJ, Coulson JC, Colebrook JM (1990) Parallel long-term trends across four marine trophic levels and weather. Nature 347:753-755

Ainley DG, Hyrenbach KD (2010) Top-down and bottom-up factors affecting seabird population trends in the California current system (1985-2006). Prog Oceanogr 84: 242-254

Ainley DG, Russell J, Jenouvrier S, Woehler E, Lyver PO'B, Fraser WR, Kooyman GL (2010) Antarctic penguin response to habitat change as earth's troposphere reaches $2^{\circ} \mathrm{C}$ above preindustrial levels. Ecol Monogr 80: 49-66

Barbraud C, Rivalan P, Inchausti P, Nevoux M, Rolland V, Weimerskirch H (2011) Contrasted demographic responses facing future climate change in Southern Ocean seabirds. J Anim Ecol 80:89-100

Bulman CM, Condie SA, Neira FJ, Goldsworthy SD, Fulton EA (2011) The trophodynamics of small pelagic fishes in the southern Australian ecosystem and the implications for ecosystem modelling of southern temperate fisheries. Final Report for FRDC project 2008/023, CSIRO Marine and Atmospheric Research, Hobart

Burnham KP (1993) A theory for combined analysis of ringrecovery and recapture data. In: Lebreton JD, North PM (eds) Marked individuals in the study of bird population. Birkhäuser Verlag, Basel, p 199-213

Burnham KP, Anderson DR (2002) Model selection and multimodel inference: a practical information-theoretic approach, 2nd edn. Springer, New York, NY

> Catchpole EA, Freeman SN, Morgan BJT, Harris MP (1998) Integrated recovery/recapture data analysis. Biometrics 54:33-46

Chambers LE, Devney C, Congdon BC, Dunlop N, Woehler EJ, Dann P (2011) Observed and predicted impacts of climate on Australian seabirds. Emu 111:235-251

Cormack RM (1964) Estimates of survival from the sighting of marked animals. Biometrika 51:429-438

Cullen JM, Chambers LE, Coutin PC, Dann P (2009) Predicting onset and success of breeding in little penguins Eudyptula minor from ocean temperatures. Mar Ecol Prog Ser 378:269-278

Dann P (1992) Distribution, population trends and factors influencing the population size of little penguins Eudyptula minor on Phillip Island, Victoria. Emu 91:263-272

Dann P, Cullen JM (1990) Survival, patterns of reproduction and lifetime reproductive success in little blue penguins (Eudyptula minor) in Victoria, Australia. In: Davis L, Darby J (eds) Penguin biology. Academic Press, San Diego, CA, p 63-84
Dann P, Norman FI (2006) Population regulation in little penguins (Eudyptula minor): the role of intraspecific competition for nesting sites and food during breeding. Emu 106:289-296

> Dann P, Cullen JM, Thoday R, Jessop R (1992) The movements and patterns of mortality at sea of little penguins Eudyptula minor from Phillip Island, Victoria. Emu 91: 278-286

Dann P, Cullen JM, Weir I (1996) National review of the conservation status and management of Australian little penguin colonies. Australian Nature Conservation Agency, Canberra

Federer WT (1955) Experimental designs, theory and application. Macmillan, New York, NY

> Frederiksen M, Edwards M, Mavor RA, Wanless S (2007) Regional and annual variation in black-legged kittiwake breeding productivity is related to sea surface temperature. Mar Ecol Prog Ser 350:137-143

Ganendran LB, Sidhu LA, Catchpole EA, Dann P, Chambers LE (2011) The effect of directional wind components on survival of little penguins Eudyptula minor. In: McLean W, Roberts AJ (eds) Proceedings of the 15th biennial computational techniques and applications conference, CTAC-2010, Sydney. ANZIAM J 52:C949-C967

Gibbs CF (1992) Oceanography of Bass Strait: implications for the food supply of little penguins Eudyptula minor. Emu 91:395-401

Gibbs CF, Tomczak M Jr, Longmore AR (1986) The nutrient regime of Bass Strait. Aust J Mar Freshwater Res 37: 451-466

Gjerdrum C, Vallée AMJ, St Clair CC, Bertram DF, Ryder JL, Blackburn GS (2003) Tufted puffin reproduction reveals ocean climate variability. Proc Natl Acad Sci USA 100:9377-9382

Guinet C, Chastel O, Koudil M, Durbec JP, Jouventin P (1998) Effects of warm sea-surface temperature anomalies on the blue petrel at the Kerguelen Islands. Proc R Soc Lond B 265:1001-1006

Harrigan KE (1992) Causes of mortality of little penguins Eudyptula minor in Victoria. Emu 91:273-277

> Harris MP, Anker-Nilssen T, McCleery RH, Erikstad KE, Shaw DN, Grosbois V (2005) Effect of wintering area and climate on the survival of adult Atlantic puffins Fratercula arctica in the eastern Atlantic. Mar Ecol Prog Ser 297:283-296

Hinrichsen HH, Lehmann A, Petereit C, Schmidt J (2007) Correlation analyses of Baltic Sea winter water mass formation and its impact on secondary and tertiary production. Oceanologia 49:381-395

Hobday A, Poloczanska E, Matear R (2008) Introduction: climate and Australian fisheries and aquaculture. In: Hobday AJ, Poloczanska ES, Matear RJ (eds) Implications of climate change for Australian fisheries and aquaculture: a preliminary assessment. Report to the Department of Climate Change, Canberra, p 1-16

> Inchausti P, Guinet C, Koudil M, Durbec JP and others (2003) Inter-annual variability in the breeding performance of seabirds in relation to oceanographic anomalies that affect the Crozet and the Kerguelen sectors of the Southern Ocean. J Avian Biol 34:170-176

Irons D, Anker-Nilssen T, Gaston AJ, Byrd GV and others (2008) Fluctuations in circumpolar seabird populations linked to climate oscillations. Glob Change Biol 14: 1455-1463

> Jolly GM (1965) Explicit estimates from capture-recapture 
data with both death and immigration: stochastic model. Biometrika 52:225-247

Kitaysky AS, Elena G, Golubova EG (2000) Climate change causes contrasting trends in reproductive performance of planktivorous and piscivorous alcids. J Anim Ecol 69: 248-262

McCullagh P, Nelder JA (1989) Generalized linear models, 2nd edn. Chapman \& Hall, London

McCutcheon C, Dann P, Salton M, Renwick L, Hoskins AJ, Gormley AM, Arnould JPY (2011) The foraging range of little penguins (Eudyptula minor) during winter. Emu 111:321-329

Mickelson MJ, Dann P, Cullen JM (1992) Sea temperature in Bass Strait and breeding success of the little penguin Eudyptula minor at Phillip Island, south-eastern Australia. Emu 91:355-368

Middleton JF, Black KP (1994) The low frequency circulation in and around Bass Strait: a numerical study. Cont Shelf Res 14:1495-1521

Mills JA, Yarrall JW, Bradford-Grieve JM, Uddstrom MJ, Renwick JA, Merila J (2008) The impact of climate fluctuation on food availability and reproductive performance of the planktivorous red-billed gull Larus novaehollandiae scopulinus. J Anim Ecol 77:1129-1142

Moe B, Stempniewicz L, Jakubas D, Angelier F and others (2009) Climate change and phenological responses of two seabird species breeding in the high-Arctic. Mar Ecol Prog Ser 393:235-246

Newell BS (1966) Seasonal changes in the hydrological and biological environments off Port Hacking, Sydney. Aust J Mar Freshwater Res 17:77-92

Poloczanska ES, Babcock RC, Butler A, Hobday AJ and others (2007) Climate change and Australian marine life. Oceanogr Mar Biol Annu Rev 45:407-478

Reilly PN, Cullen JM (1981) The little penguin Eudyptula minor in Victoria. II. Breeding. Emu 81:1-19

Reilly PN, Cullen JM (1982) The little penguin Eudyptula minor in Victoria. III. Dispersal of chicks and survival after banding. Emu 82:137-142

Ridgway K, Hill K (2009) The East Australian Current. In: Poloczanska ES, Hobday AJ, Richardson AJ (eds) A marine climate change impacts and adaptation report card for Australia 2009. Publication 05/09, National Climate Change Adaptation Research Facility, Southport, QLD

Rolland V, Barbraud C, Weimerskirch H (2008) Combined effects of fisheries and climate on a migratory long-lived marine predator. J Appl Ecol 45:4-13

> Ropert-Coudert Y, Kato A, Chiaradia A (2009) Impact of small-scale environmental perturbations on local marine food resources: a case study of a predator, the little penguin. Proc R Soc Lond B 276:4105-4109

Sandery PA (2007) Seasonal variability of water mass properties in Bass Strait: three-dimensional oceanographic modelling studies. PhD thesis, Flinders University, Adelaide

Sandvik H, Erikstad KE, Barrett RT, Yoccoz NG (2005) The effect of climate on adult survival in five species of North Atlantic seabirds. J Anim Ecol 74:817-831

Seber GAF (1965) A note on the multiple recapture census. Biometrika 52:249-259

Sidhu LA (2007) Analysis of recovery-recapture data for little penguins. PhD thesis, University of New South Wales at the Australian Defence Force Academy, Canberra

Sidhu LA, Catchpole EA, Dann P (2007) Mark-recapturerecovery modelling and age-related survival in little penguins Eudyptula minor. Auk 124:815-827

Sidhu LA, Catchpole EA, Dann P (2011) Modelling banding effect and tag loss for little penguins Eudyptula minor. In: McLean W, Roberts AJ (eds) Proceedings of the 15th biennial computational techniques and applications conference, CTAC-2010. ANZIAM J 52:C206-C221

Sydeman WJ, Bograd SJ (2009) Marine ecosystems, climate and phenology: introduction. Mar Ecol Prog Ser 393: 185-188

Tomczak M Jr (1985) The Bass Strait water cascade during winter 1981. Cont Shelf Res 4:255-278

Tomczak M Jr (1987) The Bass Strait water cascade during summer 1981-1982. Cont Shelf Res 7:561-572

> Votier SC, Hatchwell BJ, Beckerman A, McCleery RH and others (2005) Oil pollution and climate have wide-scale impacts on seabird demographics. Ecol Lett 8:1157-1164

Votier SC, Birkhead TR, Oro D, Trinder M and others (2008) Recruitment and survival of immature seabirds in relation to oil spills and climate variability. J Anim Ecol 77: 974-983

Weimerskirch H, Ancel A, Caloin M, Zahariev A, Spagiari J, Kersten M, Chastel O (2003) Foraging efficiency and adjustment of energy expenditure in a pelagic seabird provisioning its chick. J Anim Ecol 72:500-508

Zeldis JR, Oldman J, Ballara SL, Richards LA (2005) Physical fluxes, pelagic ecosystem structure, and larval fish survival in Hauraki Gulf, New Zealand. Can J Fish Aquat Sci 62:593-610

Proofs received from author(s): April 23, 2012 